\title{
Behavioral Interventions to Improve Home-Based Office-Workers' Health
}

\author{
Nina Bartmann ${ }^{1}$ (D) . Jonathan N. Cloughesy ${ }^{1}$ (D) Birgit M. Probst ${ }^{2}$. \\ Giorgia Romagnoli ${ }^{3} \cdot$ Andrej Woerner $^{4}$
}

Accepted: 4 November 2021 / Published online: 13 January 2022

(c) Associação Brasileira de Psicologia 2021

\begin{abstract}
Many organizations have traditionally supported their employees' physical and mental health through a variety of office-based programs and interventions. The shift from in-office work to working from home, which has been accelerated by the COVID-19 pandemic, requires organizations to update their toolbox to continue supporting a healthy and happy workforce. In this paper, we review research on successful, evidence-based interventions in four key areas of physical and mental health: physical activity and sedentary behavior, nutrition, loneliness, and stress. We show how organizations could adapt these interventions to a home-based office environment and conclude by highlighting areas of future research, as well as by discussing the role of health professionals and policymakers in designing effective interventions for the future of work.
\end{abstract}

Keywords Behavioral interventions $\cdot$ Employee well-being $\cdot$ Remote work $\cdot$ Physical health $\cdot$ Mental health

The World Health Organization defines health as a "state of complete physical, mental and social well-being and not merely the absence of disease or infirmity" (WHO, 2021). Leading a healthy lifestyle is not only closely connected with happiness (Mujcic \& Oswald, 2016; Netz et al., 2005) but can decrease the rate of aging (Goetzel et al., 2011) and extend life expectancy by up to 14 years (Liu et al., 2018).

Nina Bartmann

nina.bartmann@duke.edu

1 Center for Advanced Hindsight, Duke University, 334 Blackwell Street, Durham, NC 27701, USA

2 Technical University of Munich, Munich, Germany

3 University of Amsterdam, Amsterdam, The Netherlands

4 Ludwig Maximilian University of Munich, Munich, Germany 
Across Europe and the USA, the average full-time worker spends roughly half of her waking hours at work (Giattino et al., 2013), placing employers in a unique position to influence employees' health and well-being. Aside from health being intrinsically valuable and recognized as a universal human right, employers benefit directly from investing in the health of their workforce. Healthier employees are more productive, more satisfied with their job, and more likely to innovate at work (Huhtala \& Parzefall, 2007; Wright \& Huang, 2012). Not surprisingly, many organizations have implemented research-backed interventions to improve the physical and mental health of their workforce (see e.g., Chance et al., 2016; Slaunwhite et al., 2009; Venema et al., 2018).

After SARS-CoV-2 (COVID-19) was declared a global pandemic (WHO, 2020b), work routines were fundamentally altered. While lockdowns, social distancing measures, and travel restrictions brought new challenges for our personal lives, full-time work from home-also referred to as "home-office" or "teleworking"experienced a surge among non-essential office-based workers across the globe. While merely $15 \%$ of those employed in the European Union (EU) had ever worked from home prior to the outbreak of the COVID-19 pandemic (European Commission, 2020), this number jumped to almost 40\% as of July 2020 (Eurofound, 2020), albeit with considerable variation across occupations and geographical areas. Working from home is predicted to outlive the COVID-19 pandemic in some form and will likely remain a permanent feature for many traditionally office-based occupations (Hickman \& Robison, 2020). The transition to a home-office environment has rendered many established workplace interventions impractical or no longer feasible, demanding a critical rethinking of how organizations can support their employees' health and well-being.

Based on the existing literature of successful interventions related to physical and mental health, this paper intends to equip organizations with effective and easily adaptable tools to continue improving the health of their employees within the workfrom-home setting. The paper also highlights areas where new evidence is needed, serving as a possible reference for researchers and policy makers. We organize our contributions around two major areas: physical health and mental health.

\section{Selection Criteria}

The World Health Organization's definition of health-a "state of complete physical, mental and social well-being and not merely the absence of disease or infirmity" (WHO, 2021)—served as a basis in identifying the two major health areas that are the focus of this paper: physical health and mental health. In our conceptualization, mental health includes social well-being.

Based on a review of the work-from-home literature, we identified the following four pillars as key health factors consistently impacted by the transition to a homeoffice environment due to the COVID-19 pandemic: physical activity and sedentary behavior, nutrition, loneliness, and stress (Ammar et al., 2020a, 2020b; Bennett et al., 2021; Buffer, 2020; Meyer et al., 2020; Salari et al., 2020). The following criteria were used to map the described interventions in each area: interventions (a) are 
easily adaptable (in terms of cost and effort) to office-based employees now working from home, (b) support one of the four health pillars most affected by teleworking (physical activity and sedentary behaviour, nutrition, loneliness, and stress), and (c) have proven effective in scientific studies. Interventions were identified via the Google Scholar search engine. Interventions meeting all three criteria were included in the paper. ${ }^{1}$

\section{Critical Areas and Interventions}

\section{Physical Health}

Physical inactivity and unhealthy eating represent two of the leading risk factors for non-communicable diseases, such as cardiovascular disease, diabetes, and obesity (Cecchini et al., 2010; Lee et al., 2012). Poor employee physical health resulting from these risk factors also poses substantial concerns for employers due to increased absenteeism and loss of productivity (Proper \& van Mechelen, 2008).

\section{Physical Activity and Sedentary Behavior}

As work becomes increasingly sedentary in nature, a growing number of desk-based workers are at an elevated risk of obesity, chronic illness, and premature mortality (Chau et al., 2013; Church et al., 2011). To cope with the health risks of physical inactivity, it is necessary to increase energy expenditure while decreasing sedentary behavior (Hamilton et al., 2008). Specifically, adults should engage in at least $75 \mathrm{~min}$ of vigorous or $150 \mathrm{~min}$ of moderate physical activity per week (WHO, 2020a) and should regularly break up their sitting behavior (i.e., at least $2 \mathrm{~h}$ of accumulated standing or light physical activity per day (Buckley et al., 2015)). However, the COVID-19 pandemic has worsened the problem, as evidenced by a reduction of physical activity (Ammar et al., 2020a; Meyer et al., 2020), decreased step counts (Tison et al., 2020), and increased time spent sedentary (Ammar et al., 2020a). While some of these effects are likely to be temporary (e.g., the COVID-19-related closures of gym facilities), others are bound to remain as a permanent feature of working from home (e.g., lack of physical activity connected to a decrease in active commuting). Updated recommendations and interventions are needed to promote physical activity and reduce sedentary behavior of employees working from home, during and after work hours.

Active Workstations One of the most widely studied methods to reduce sedentary behavior during the workday is the provision of alternative workstations that allow employees to stand or be active while working. Although traditional workstations

\footnotetext{
1 The interventions described in this paper are illustrative rather than exhaustive. We do not intend to document all possible interventions that meet our criteria, but instead describe a series of interventions that may be relevant to organizations and policy-makers.
} 
have been designed for sitting, the use of sit-stand workstations can reduce time spent sitting by around $100 \mathrm{~min}$ per day (Shrestha et al., 2018). Although less studied, evidence suggests that active workstations, which allow the user to engage in physical activity such as walking or cycling while working (Elmer \& Martin, 2014), may be effective at reducing sedentary behaviour (Schuna Jr et al., 2014; John et al., 2011). While work from home means that employers lose full control over the workstation chosen by their employees, employers may consider providing equipment or advice to improve their employees' choice for a home workstation. For example, standing desk converters (or desk risers) are both cost-effective and easily adaptable to the variety of domestic architectures that host home offices.

Active Meetings In addition to altering workstations, organizations may consider shifting norms around sedentary behavior during the workday. For example, team managers and leaders could actively promote a culture of standing during meetings (Danquah \& Tolstrup, 2020; Neuhaus et al., 2014). Encouraging active meetings, such as by designating specific meetings as "desk-free," indicating that employees are recommended to join the meeting via their mobile devices while taking a walk or by integrating periods of active movement and/or stretching into traditional meetings, may allow employees more opportunities to be physically active during the workday while creating a team norm of activity during the workday (Kling et al., 2016). Although walking meetings may face a number of logistical barriers (Danquah \& Tolstrup, 2020), recommending employees to go on walks during periods of ideation may be especially beneficial for physical health and creativity, as research indicates that walking can improve creative thinking (Oppezzo \& Schwartz, 2014). Additional support from team leaders, such as a weekly recommendation, can help cultivate an environment that supports employees in being active whenever possible (Healy et al., 2013; Quintiliani et al., 2007).

Temptation Bundling A promising way to boost physical activity after working hours is to help employees combine exercising with a typically more pleasant activity, such as streaming TV shows or listening to audiobooks (Milkman et al., 2014 and Kirgios et al., 2020). In the literature, this approach is referred to as temptation bundling. Given that leading streaming websites offer subscriptions for less than $\$ 10$ a month, providing employees with such a subscription and encouraging them to combine watching and exercising could be a simple and inexpensive way to increase physical activity at home. Alternatively, budget-tight employers can leverage the surge in the utilization of streaming services (Statista, 2020) and simply recommend employees who have already independently chosen these subscriptions to be physically active during streaming time.

Monetary Incentives A second or complementary approach to promote physical activity of employees after work hours is to pay people for reaching pre-specified daily (or weekly) physical activity targets. The literature has identified some guiding principles on how to best offer monetary incentives, namely, that financial incentives should be targeted at inactive people, can be modest in size but should be offered 
for longer periods (Mitchell et al., 2020). For walking, Bachireddy et al. (2019) find that constant incentives work better than incentives that are decreasing or increasing in size over time. To keep costs low, an employer should consider offering threshold incentives, i.e. people are only paid if they manage to surpass a certain minimum level of activity (Aggarwal et al., 2020). Yet, the key feature that all principles have in common is the requirement that the incentivized behavior be verified. The rise of smartphone technology and wearable trackers has made it easy to count one's daily steps and to share this data with others. While monetary incentives have proven effective in helping people change their behavior in various healthrelated areas such as walking, exercising in the gym, losing weight, quitting smoking, and reducing alcohol consumption (see e.g. Aggarwal et al., 2020; Augurzky et al., 2018; Bachireddy et al., 2019; Burger \& Lynham, 2010; Charness \& Gneezy, 2009; Giné et al., 2010; Halpern et al., 2015; Royer et al., 2015; Schilbach, 2019), we argue that walking targets may be a particularly fruitful domain. Walking is a generally accessible activity requiring no extra equipment or special location and as such is particularly cost-effective. Moreover, walking targets may be particularly easy to implement within a work-from-home setting, where walking can be more organically incorporated into errands and household chores, compared to a traditional office setting.

\section{Nutrition}

Healthy eating is essential to maintaining good health. For example, a daily intake of at least five portions of fruit and vegetables, less than $50 \mathrm{~g}$ of sugars, and the reduction of fat and salt is recommended (WHO, 2020a). Part of a healthy diet also includes a total daily water intake of at least 4-6 cups (1-1.5 L) to help manage body weight and prevent dehydration (Harvard Health Publishing, 2016). On any given day, we make approximately 200 food-related decisions (Wansink \& Sobal, 2007). However, we are often not aware that we are making these decisions which means these choices can be heavily influenced by the choice architecture of our physical environments. Historically, organizations have taken advantage of this fact by making explicit changes to both workplace break rooms (Chance et al., 2016) and cafeteria layout and labelling (Chance et al., 2016; Thorndike et al., 2012; Velema et al., 2018) to effectively steer employees toward healthier food choices. While organizations no longer have the ability to harness the power of choice architecture to influence nutritional habits of their employees working at home, we argue that they are still in a position to play a key role in encouraging healthy nutrition through other means.

Visual Reminders Visual reminders are a common and powerful method to subconsciously influence individuals' drink and food choices. For example, close proximity of water to an office-workers' desk was found to increase the amount that the employee drank throughout their workday (Wildermuth, 2018). While visual cues were traditionally disseminated within the physical spaces of the office environment, the principle can also be adapted to the home-office. For example, providing 
a (recyclable) water bottle to employees working from home, and asking them to "bring it" to conference calls, could result in a similar effect.

Food Vouchers Another promising intervention is to reallocate resources previously designated for company cafeterias to food vouchers for home-delivery of healthy foods, such as fruits and vegetables. Such food vouchers decrease the relative price of healthy foods compared to unhealthy foods. Not surprisingly, the relative price change has shown to increase the consumption of healthy food (Brownback et al., 2020; Sadoff \& Samek, 2019). Further, evidence suggests that such a push towards eating healthier can lead to a persistent change in food preferences (Sadoff \& Samek, 2019). The positive effects of healthy food vouchers can be amplified not only by letting people decide on their food orders in advance (Brownback et al., 2020; Sadoff et al., 2020) but by providing information about the benefits of eating healthily before people make their orders (Sadoff \& Samek, 2019). Lastly, food vouchers for healthy foods and ingredients can also stimulate employees to prepare more homecooked meals, which has been shown to be associated with the consumption of a healthier diet (Mills et al., 2017).

\section{Mental Health}

The need to address mental health at the workplace has been identified by several authors (Goetzel et al., 2018; LaMontagne et al., 2014; Memish et al., 2017; Page $\&$ Vella-Brodrick, 2009). Poor employee mental health not only represents a huge burden for the individual but has negative economic consequences for companies due to absenteeism and loss of productivity (Birnbaum et al., 2010; Evans-Lacko \& Knapp, 2016).

Moreover, COVID-19 has brought about a huge additional mental burden with increasing levels of anxiety, depression (Salari et al., 2020), loneliness, and insomnia (Ammar et al., 2020b). While some of the negative effects on mental well-being are likely to be temporary (e.g., COVID-19-related anxiety about job-security or health), others may remain post-COVID-19, in particular the increased risk of loneliness (Buffer, 2020) and stress associated with working from home. It is therefore important to equip organizations with mental health interventions that are effective within a work-from-home environment.

\section{Loneliness}

Social interactions are important contributors not only to good physical health, mental health, and longevity (Umberson \& Karas Montez, 2010) but also to overall employee happiness (Rosales, 2015). When working fully remotely, employees lack in-person social interactions with their colleagues, and in particular miss out on meaningful connections (Gallup, 2017). Fewer in-person interaction can increase feelings of loneliness or isolation, which is a major driver of anxiety and depression (Slack, 2020; Mental Health America, 2020). While substantive and meaningful conversations are the gold standard in terms of happiness and well-being, it is still 
significantly better to engage in small talk than in no talk at all (Milek et al., 2018). When shifting to a (partial) work-from-home environment, employees lose out on the many spontaneous opportunities for small talk. Therefore, it is crucial that managers are intentional about creating opportunities for co-workers to connect.

Embedding Opportunities for Connection into Work Meetings In practice, team leads or managers could reserve the first few minutes of a weekly meeting for relationship building (Grenny \& Maxfield, 2017). During that time, employees could share good personal and professional news (Gable et al., 2004) or express their gratitude to their colleagues (Algoe, 2012) as interactions that involve sharing positive emotions have shown to build particularly strong relationships (Algoe, 2019). Alternatively, those first minutes can be dedicated toward the practice of self-disclosure, such as the Generating Closeness Task, a series of short questions with increasing levels of self-disclosure that has been proven to increase closeness between people (Aron et al., 1997).

Digital Communication Platforms For organizations in industries with limited meeting opportunities, or for those seeking to provide additional opportunities to connect, popular communication platforms, such as Slack or Microsoft Teams, could serve as a platform to boost (positive) connection. On Slack, for example, employees could be encouraged to post a message in a "Gratitude Channel" at the end of every workweek, publicly thanking a colleague for their help or hard work throughout the week. Other sources have suggested using these communication platforms to share recipes, articles, or snapshots (Groysberg \& Abrahams, 2020).

\section{Stress}

Work-related stress is a prevalent yet detrimental experience for desk-based workers (Shirom, 2003). Although working from home may relieve employees from a variety of traditional stressors associated with in-office work, e.g., long commuting times (Chatterjee et al., 2017; Zhang \& Feinzig, 2017), working from home can also create new stressors for employees. For example, by increasing workers' reliance on digital communication, employees working from home may be expected to more carefully monitor e-mail and other sources of internet-based communication. An overabundance of digital communication, which includes the increased use of teleconferencing, can contribute to a perception of work overload (Gupta et al., 2013) and harm employee well-being (Akbar et al., 2019; Keller et al., 2020). Working from home may also lead to distractions unique to the physical home environment, such as interruptions from a family member or the need to tend to other home-based demands (Delanoeije et al., 2019). Indeed, research suggests that the lack of physical and psychological boundaries separating work from home can make it difficult to disconnect from work and result in longer work hours (Diaz et al., 2012). The tendency to engage in work behavior beyond typical work hours has been associated with increased stress (Mazmanian et al., 2013), burnout (Wright et al., 2014), emotional exhaustion (Xie et al., 2018), and work-life conflict (Derks et al., 2015; Diaz et al., 2012). The following 
section describes a selection of strategies that organizations and team managers can use to prevent or reduce the negative impact of stress on employees.

Mindfulness and Positive Psychology Interventions Mindfulness-based and positive psychology interventions represent one promising approach to help employees reduce stress while working from home. In one study, employees experienced reductions in work-life conflict, a major source of stress, after being provided with a 6-week mindfulness-based program (Slutsky et al., 2019). A similar study found that there was no difference in the reduction of stress between an in-person and online program (Wolever et al., 2012). This suggests that mindfulness programs delivered virtually to employees working from home may be viable and effective.

In addition to mindfulness-based programs, positive psychology interventions can be adapted to protect employees from the harmful effects of work-related stress. For example, workers that reflected daily on three good events that happened during the workday over the course of 1-week experienced reduced stress and reported a greater ability to detach from work in the evening (Bono et al., 2013). Beyond reflection, engaging in a ritual or routine while commuting is suggested to help employees manage their stress (Gino et al., 2017). Although employees do not commute when working from home, setting time aside for a morning routine may help workers reap the benefits of this process. Lastly, research has demonstrated that feeling connected with nature is associated with improved well-being (Cervinka et al., 2012). Indeed, the mere presence of an indoor plant at a workstation can help reduce employees' stress (Toyoda et al., 2020). Employers may consider providing their employees with small plants as a simple intervention to mitigate the harmful effects of work-related stress.

Encourage Breaks from Work The positive relationship between taking breaks from work and employee well-being has been found in a variety of settings, such as taking micro-breaks, lunch breaks, weekends off, or vacations (Bennett et al., 2020; Bosch et al., 2018; De Bloom et al., 2013; Ragsdale \& Beehr, 2016). For example, introducing a company-wide policy of reducing the standard 1-h meeting to $45 \mathrm{~min}$ (NU, 2021) is a promising avenue to not only help with productivity but to free up time for micro-breaks. Designating meeting-free time during lunch hours signals to employees to take a break, eat lunch, and spend some time outdoors as exposure to nature has been shown to have a close association with happiness and life satisfaction (Capaldi et al., 2014; McMahan \& Estes, 2015).

While micro-breaks and lunch breaks are taking place during work hours, employers also have leverage over how much time employees spend resting outside of work hours. Even though vacations boost happiness, productivity and creativity and have also shown to reduce the likelihood of developing mental health issues (Carmichael, 2015), over half of all American employees reported having unused vacation days at the end of the year (US Travel, 2019). Organizations can encourage employees to take their vacation days by requiring employees to take time off (Perlow \& Porter, 2009) or, borrowing from the vaccination literature, by defaulting employees into vacation days (Chapman et al., 2016). Depending on the industry, 
default scheduling of vacation days can be coordinated so that every employee is off at the same time or phased out to ensure critical business functions are maintained at all times. Alternatively, limiting the number of days that can be rolled over to the next year, limiting pay-outs for unused vacation days, and making sure employees are sufficiently trained to take over tasks of a vacationing colleague can encourage the uptake of time-off.

Overcoming Meeting Fatigue The number of attended meetings on a workday is positively related to feelings of fatigue and heightened subjective workload (Luong $\&$ Rogelberg, 2005). While this has been found in pre-COVID-19 times, the inevitable use of teleconferencing while working from home can be additionally tiresome for employees. While the term "Zoom fatigue" first appeared in popular press in 2020 (Morris, 2020; Reinach Wolf, 2020), more recently, academic publications picked up on the topic (Bailenson, 2021; Peper et al., 2021) as well.

"Zoom fatigue" may occur due to, for example, eye gaze at a close distance, lack of body language and non-verbal cues, increased self-evaluation, and physical constraints (Bailenson, 2021; Peper et al., 2021). Such stressors could be tackled by simply adjusting Zoom's settings, for example, by hiding the window of one's own face or by doing "audio-only" Zoom meetings or phone calls where possible (Bailenson, 2021). Companies could also encourage employees to use an external keyboard to increase mobility (Bailenson, 2021), to regularly relax their eyes by looking out of the window (Peper et al., 2021) or implement a meeting-free week as has been recently done by a Dutch health insurer (NU, 2021). These suggestions have not yet been tested experimentally within a Zoom setting, but are based on previous research and therefore are promising ways to overcome meeting fatigue (Bailenson, 2021).

\section{Concluding Remarks}

Many organizations have traditionally supported their employees' physical and mental health through a variety of office-based programs and interventions. While the COVID-19 pandemic has led to a sudden shift from in-office work to working from home, part-time working from home is likely to persist after the crisis subsides as it is not only preferred by most employees and employers (Parker et al., 2020) but can also make employees less stressed, happier, more loyal to employers and better able to achieve a good work-life balance (OWL Labs, 2019). The shift towards a hybrid model $^{2}$ requires organizations to update their toolbox to continue supporting

\footnotetext{
${ }^{2}$ The optimal amount of time spent working at home is unclear; engagement is suggested to be highest when employees spend three to four days out of a five-day workweek working from home (Hickman and Robison, 2020), while job and life satisfaction seem to be highest when working from home for two days per week (Shockley, 2014). More than 2.5 days of work-from-home a week may benefit work-family relationship, but harm relationships with co-workers (Gajendran and Harrison, 2007).
} 
a healthy workforce. This paper has reviewed research on successful interventions related to physical and mental health and has discussed how organizations could adapt these interventions to a home-based office environment.

While the focus of the paper is on organization-led interventions, researchers, health professionals, and legislators can also crucially contribute to a healthy home-based workforce. First, more research is needed to verify that the adaptations of existing interventions work as expected in a home-office environment. Researchers should also explore new interventions that leverage the specificity of the homeoffice and the technological advancements that are being developed to facilitate the work-from-home transition.

Second, health professionals could improve home-based workers' health in complementary areas. While organization-initiated interventions can improve physical activity, nutrition, loneliness, and stress, other critical issues, such as addictive behavior, might become more severe when employees work from home. Recent evidence suggests that alcohol and drug consumption, as well as smoking, has surged in connection to the COVID-19 pandemic (Dubey et al., 2020). It is unclear to what extent the surge in addictive behavior will persist after the COVID-19 pandemic is over, although the link between isolation and addictive behavior warrant attention (Hosseinbor et al., 2014). Since the nature of these problems is too complex to be autonomously handled by organizations, these areas require specialized medical monitoring and intervention by health professionals.

Lastly, legislators can play a crucial role in improving the health of employees working from home. Some key aspects of health and well-being of the workforce can be protected more effectively at the legislative rather than the organization level. In most countries, specific legislation protects workers' rights to a safe and healthy workplace environment. Some of these regulations (e.g., those concerning workplace ergonomics and employer's liability insurance) may need adaptation and extension to the home-office environment. More specifically, legislators should verify that the responsibility of employers is clarified and potentially extended to make sure employees are insured against injuries incurred when working from home and that home-offices are safe and conducive to their health and well-being.

As office-based work transitions to a hybrid home and office-based model, organizations have the unique opportunity to critically examine ways to maintain and improve their employees' health from a distance. We hope this paper offers a starting point for doing so, providing organizations, managers, policy makers and health professionals with a set of behavioral interventions to make the home-office a viable and healthy alternative to traditional office-working in the long run.

\section{Data Availability Statement}

Data sharing not applicable to this article as no datasets were generated or analyzed during the current study.

Funding This research was supported by Zilveren Kruis Zorgverzekeringen N.V. 


\section{Declarations}

Informed Consent Statement Not applicable.

Conflict of Interest The authors declare no competing interests.

\section{References}

Aggarwal, S., Dizon-Ross, R., \& Zucker, A. D. (2020). Incentivizing behavioral change: The role of time preferences (Tech. Rep.). National Bureau of Economic Research.

Akbar, F., Bayraktaroglu, A. E., Buddharaju, P., Da Cunha Silva, D. R., Gao, G., Grover,T., . . others (2019). Email makes you sweat: Examining email interruptions and stress using thermal imaging. In Proceedings of the 2019 chi conference on human factors in computing systems (pp. 1-14).

Algoe, S. B. (2012). Find, remind, and bind: The functions of gratitude in everyday relationships. Social and Personality Psychology Compass, 6(6), 455-469.

Algoe, S. B. (2019). Positive interpersonal processes. Current Directions in Psychological Science, 28(2), 183-188.

Ammar, A., Brach, M., Trabelsi, K., Chtourou, H., Boukhris, O., Masmoudi, L., ..., others (2020). Effects of covid-19 home confinement on eating behaviour and physical activity: results of the eclbcovid19 international online survey. Nutrients, 12(6), 1583.

Ammar, A., Trabelsi, K., Brach, M., Chtourou, H., Boukhris, O., Masmoudi, L., . . . others (2020). Effects of home confinement on mental health and lifestyle behaviours during the covid-19 outbreak: Insight from the "eclb-covid19" multi countries survey. MedRxiv.

Aron, A., Melinat, E., Aron, E. N., Vallone, R. D., \& Bator, R. J. (1997). The experimental generation of interpersonal closeness: A procedure and some preliminary findings. Personality and Social Psychology Bulletin, 23(4), 363-377.

Augurzky, B., Bauer, T. K., Reichert, A. R., Schmidt, C. M., \& Tauchmann, H. (2018). Habit formation, obesity, and cash rewards (No. 750). Ruhr Economic Papers.

Bachireddy, C., Joung, A., John, L. K., Gino, F., Tuckfield, B., Foschini, L., \& Milkman, K. L. (2019). Effect of different financial incentive structures on promoting physical activity among adults: A randomized clinical trial. JAMA Network Open, 2(8), e199863-e199863.

Bailenson, J. N. (2021). Nonverbal overload: A theoretical argument for the causes of Zoom fatigue. Technology, Mind, and Behavior, 2(1).

Bennett, A. A., Gabriel, A. S., \& Calderwood, C. (2020). Examining the interplay of micro-break durations and activities for employee recovery: A mixed-methods investigation. Journal of Occupational Health Psychology, 25(2), 126.

Bennett, G., Young, E., Butler, I. \& Coe, S. (2021). The Impact of Lockdown During the COVID-19 Outbreak on Dietary Habits in Various Population Groups: A Scoping Review. Frontiers in Nutrition, 8.https://doi.org/10.3389/fnut.2021.626432

Birnbaum, H. G., Kessler, R. C., Kelley, D., Ben-Hamadi, R., Joish, V. N., \& Greenberg, P. E. (2010). Employer burden of mild, moderate, and severe major depressive disorder: Mental health services utilization and costs, and work performance. Depression and Anxiety, 27(1), 78-89.

Bono, J. E., Glomb, T. M., Shen, W., Kim, E., \& Koch, A. J. (2013). Building positive resources: Effects of positive events and positive reflection on work stress and health. Academy of Management Journal, 56(6), 1601-1627.

Bosch, C., Sonnentag, S., \& Pinck, A. S. (2018). What makes for a good break? A diary study on recovery experiences during lunch break. Journal of Occupational and Organizational Psychology, 91(1), 134-157.

Brownback, A., Imas, A., \& Kuhn, M. (2020). Behavioral food subsidies. Available at SSRN 3422272.

Buckley, J. P., Hedge, A., Yates, T., Copeland, R. J., Loosemore, M., Hamer, M., \& ...Dunstan, D. W. (2015). The sedentary office: An expert statement on the growing case for change towards better health and productivity. British Journal of Sports Medicine, 49(21), 1357-1362.

Buffer. (2020). The 2020 state of remote work. https://lp.buffer.com/state-of-remote-work-2020?utm_ source=angellist, Accessed: 2021-03-03. 
Burger, N., \& Lynham, J. (2010). Betting on weight loss. . and losing: personal gambles as commitment mechanisms. Applied Economics Letters, 17(12), 1161-1166.

Capaldi, C. A., Dopko, R. L., \& Zelenski, J. M. (2014). The relationship between nature connectedness and happiness: A meta-analysis. Frontiers in Psychology, 5, 976.

Carmichael, S. G. (2015). The research is clear: Long hours backfire for people and for companies. Harvard Business Review, 19.

Cecchini, M., Sassi, F., Lauer, J. A., Lee, Y. Y., Guajardo-Barron, V., \& Chisholm, D. (2010). Tackling of unhealthy diets, physical inactivity, and obesity: Health effects and cost-effectiveness. The Lancet, 376(9754), 1775-1784.

Cervinka, R., Röderer, K., \& Hefler, E. (2012). Are nature lovers happy? on various indicators of wellbeing and connectedness with nature. Journal of Health Psychology, 17(3), 379-388.

Chance, Z., Dhar, R., Hatzis, M., \& Bakker, M. (2016). How google optimized healthy office snacks. Harvard Business Review, https://hbr.org/2016/03/how-google-uses-behavioral-economics-to-makeits-employees-healthier, Accessed: 2021-03-03.

Chapman, G. B., Li, M., Leventhal, H., \& Leventhal, E. A. (2016). Default clinic appointments promote influenza vaccination uptake without a displacement effect. Behavioral Science \& Policy, 2(2), 40-50.

Charness, G., \& Gneezy, U. (2009). Incentives to exercise. Econometrica, 77(3), 909-931.

Chatterjee, K., Clark, B., Martin, A., \& Davis, A. (2017). The commuting and wellbeing study: Understanding the impact of commuting on people's lives.

Chau, J. Y., Grunseit, A. C., Chey, T., Stamatakis, E., Brown, W. J., Matthews, C. E., ..., van der Ploeg, H. P. (2013). Daily sitting time and all-cause mortality: a meta-analysis. PloS one, 8(11), e80000.

Church, T. S., Thomas, D. M., Tudor-Locke, C., Katzmarzyk, P. T., Earnest, C. P., Rodarte, R. Q., ..., Bouchard, C. (2011). Trends over 5 decades in us occupation-related physical activity and their associations with obesity. PloS one, 6(5), e19657.

European Commission. (2020). Telework in the eu before and after the covid-19: where we were, where we head to. https://ec.europa.eu/jrc/sites/jrcsh/files/jrc120945_policy_brief_-_covid_and_telew ork_final.pdf, Accessed: 2021-03-03.

Danquah, I. H., \& Tolstrup, J. S. (2020). Standing meetings are feasible and effective in reducing sitting time among office workers-walking meetings are not: Mixed-methods results on the feasibility and effectiveness of active meetings based on data from the "take a stand!" study. International Journal of Environmental Research and Public Health, 17(5), 1713.

De Bloom, J., Geurts, S. A., \& Kompier, M. A. (2013). Vacation (after-) effects on employee health and well-being, and the role of vacation activities, experiences and sleep. Journal of Happiness Studies, 14(2), 613-633.

Delanoeije, J., Verbruggen, M., \& Germeys, L. (2019). Boundary role transitions: A day-to-day approach to explain the effects of home-based telework on work-to-home conflict and home-to-work conflict. Human Relations, 72(12), 1843-1868.

Derks, D., van Duin, D., Tims, M., \& Bakker, A. B. (2015). Smartphone use and work-home interference: The moderating role of social norms and employee work engagement. Journal of Occupational and Organizational Psychology, 88(1), 155-177.

Diaz, I., Chiaburu, D. S., Zimmerman, R. D., \& Boswell, W. R. (2012). Communication technology: Pros and cons of constant connection to work. Journal of Vocational Behavior, 80(2), 500-508.

Dubey, M. J., Ghosh, R., Chatterjee, S., Biswas, P., Chatterjee, S., \& Dubey, S. (2020). Covid-19 and addiction. Diabetes \& Metabolic Syndrome: Clinical Research \& Reviews, 14(5), 817-823.

Elmer, S. J., \& Martin, J. C. (2014). A cycling workstation to facilitate physical activity in office settings. Applied Ergonomics, 45(4), 1240-1246.

Eurofound. (2020). Living, working and covid-19. https://www.eurofound.europa.eu/sites/default/files/ef_ publication/field_ef_document/ef20059en.pdf, Accessed: 2021-03-03.

Evans-Lacko, S., \& Knapp, M. (2016). Global patterns of workplace productivity for people with depression: Absenteeism and presenteeism costs across eight diverse countries. Social Psychiatry and Psychiatric Epidemiology, 51(11), 1525-1537.

Gable, S. L., Reis, H. T., Impett, E. A., \& Asher, E. R. (2004). What do you do when things go right? the intrapersonal and interpersonal benefits of sharing positive events. Journal of Personality and Social Psychology, 87(2), 228.

Gajendran, R. S., \& Harrison, D. A. (2007). The good, the bad, and the unknown about telecommuting: Meta-analysis of psychological mediators and individual consequences. Journal of Applied Psychology, 92(6), 1524. 
Gallup. (2017). State of the american workplace. https://www.gallup.com/workplace/238085/state-ameri can-workplace-report-2017.aspx, Accessed: 2021-03-03.

Giattino, C., Ortiz-Ospina, E., \& Roser, M. (2013). Working hours. Our World in Data, https://ourwo rldindata.org/working-hours, Accessed: 2021-03-03.

Giné, X., Karlan, D., \& Zinman, J. (2010). Put your money where your butt is: A commitment contract for smoking cessation. American Economic Journal: Applied Economics, 2(4), 213-235.

Gino, F., Staats, B., Jachimowicz, J., Lee, J., \& Menges, J. (2017). Reclaim your commute. Harvard Business Review, 1.

Goetzel, R. Z., Roemer, E. C., Holingue, C., Fallin, M. D., McCleary, K., Eaton, W., \& ...others,. (2018). Mental health in the workplace: A call to action proceedings from the mental health in the workplace: Public health summit. Journal of Occupational and Environmental Medicine, 60(4), 322.

Goetzel, R. Z., Staley, P., Ogden, L., Stange, P. V., Fox, J., Spangler, J., . . others (2011). A framework for patient-centered health risk assessments: providing health promotion and disease prevention services to medicare beneficiaries.

Grenny, J., \& Maxfield, D. (2017). A study of 1,100 employees found that remote workers feel shunned and left out. Harvard Business Review, https://hbr.org/2017/11/a-study-of-1100-employees-foundthat-remote-workers-feel-shunned-and-left-out, Accessed: 2021-03-03.

Groysberg, B., \& Abrahams, R. (2020). Keep your weary workers engaged and motivated. Harvard Business School Working Knowledge, https://hbswk.hbs.edu/item/keep-covid-weary-employees-engag ed-and-motivated, Accessed: 2021-03-03.

Gupta, A., Li, H., \& Sharda, R. (2013). Should i send this message? Understanding the impact of interruptions, social hierarchy and perceived task complexity on user performance and perceived workload. Decision Support Systems, 55(1), 135-145.

Halpern, S. D., French, B., Small, D. S., Saulsgiver, K., Harhay, M. O., Audrain-McGovern, J., ..., Volpp, K. G. (2015). Randomized trial of four financial-incentive programs for smoking cessation. New England Journal of Medicine, 372(22), 2108-2117.

Hamilton, M. T., Healy, G. N., Dunstan, D. W., Zderic, T. W., \& Owen, N. (2008). Too little exercise and too much sitting: Inactivity physiology and the need for new recommendations on sedentary behavior. Current Cardiovascular Risk Reports, 2(4), 292-298.

Harvard Health Publishing. (2016). How much water should you drink? https://www.health.harvard.edu/ staying-healthy/how-much-water-should-you-drink, Accessed: 2021-03-03.

Healy, G. N., Eakin, E. G., LaMontagne, A. D., Owen, N., Winkler, E. A., Wiesner, G., et al. (2013). Reducing sitting time in office workers: Short-term efficacy of a multicomponent intervention. Preventive Medicine, 57(1), 43-48.

Hickman, A., \& Robison, J. (2020). Is working remotely effective? Gallup research says yes. Gallup, https://www.gallup.com/workplace/283985/working-remotely-effective-gallup-research-says-yes. aspx, Accessed: 2021-03-03.

Hosseinbor, M., Ardekani, S. M. Y., Bakhshani, S., \& Bakhshani, S. (2014). Emotional and social loneliness in individuals with and without substance dependence disorder. International Journal of High Risk Behaviors \& Addiction, 3(3).

Huhtala, H., \& Parzefall, M.-R. (2007). A review of employee well-being and innovative-ness: An opportunity for a mutual benefit. Creativity and innovation management,16(3), 299-306.

John, D., Thompson, D. L., Raynor, H., Bielak, K., Rider, B., \& Bassett, D. R. (2011). Treadmill workstations: A worksite physical activity intervention in overweight and obese office workers. Journal of Physical Activity and Health, 8(8), 1034-1043.

Keller, A. C., Meier, L. L., Elfering, A., \& Semmer, N. K. (2020). Please wait until I am done! Longitudinal effects of work interruptions on employee well-being. Work \& Stress, 34(2), 148-167.

Kirgios, E. L., Mandel, G. H., Park, Y., Milkman, K. L., Gromet, D. M., Kay, J. S., \& Duckworth, A. L. (2020). Teaching temptation bundling to boost exercise: A field experiment. Organizational Behavior and Human Decision Processes, 161, 20-35.

Kling, H. E., Yang, X., Messiah, S. E., Arheart, K. L., Brannan, D., \& Caban-Martinez,A. J. (2016). Peer reviewed: Opportunities for increased physical activity in the workplace: the walking meeting (wam) pilot study, Miami, 2015. Preventing Chronic Disease, 13.

OWL Labs. (2019). State of remote work 2019. https://resources.owllabs.com/state-of-remote-work/2019, Accessed: 2021-03-03.

LaMontagne, A. D., Martin, A., Page, K. M., Reavley, N. J., Noblet, A. J., Milner, A. J., ..., Smith, P. M. (2014). Workplace mental health: developing an integrated intervention approach. BMC psychiatry, 14(1), 1-11. 
Lee, I.-M., Shiroma, E. J., Lobelo, F., Puska, P., Blair, S. N., Katzmarzyk, P. T., ..., others (2012). Effect of physical inactivity on major non-communicable diseases world-wide: an analysis of burden of disease and life expectancy. The Lancet, 380(9838), 219-229.

Liu, Z., Kuo, P.-L., Horvath, S., Crimmins, E., Ferrucci, L., \& Levine, M. (2018). A new aging measure captures morbidity and mortality risk across diverse subpopulations from NHANES IV: A cohort study. PLoS medicine, 15(12), e1002718.

Luong, A., \& Rogelberg, S. G. (2005). Meetings and more meetings: The relationship between meeting load and the daily well-being of employees. Group Dynamics: Theory, Research, and Practice, 9(1), 58.

Mazmanian, M., Orlikowski, W. J., \& Yates, J. (2013). The autonomy paradox: The implications of mobile email devices for knowledge professionals. Organization Science, 24(5), 1337-1357.

McMahan, E. A., \& Estes, D. (2015). The effect of contact with natural environments on positive and negative affect: A meta-analysis. The Journal of Positive Psychology, 10(6), 507-519.

Memish, K., Martin, A., Bartlett, L., Dawkins, S., \& Sanderson, K. (2017). Workplace mental health: An international review of guidelines. Preventive Medicine, 101, 213-222.

Mental Health America. (2020). Mental health needs in the U.S. grew dramatically in 2020. https://www. mhanational.org/mental-health-needs-us-grew-dramatically-2020, Accessed: 2021-03-03.

Meyer, J., McDowell, C., Lansing, J., Brower, C., Smith, L., Tully, M., \& Herring, M. (2020). Changes in physical activity and sedentary behavior in response to covid-19 and their associations with mental health in 3052 us adults. International Journal of Environmental Research and Public Health, 17(18).

Milek, A., Butler, E. A., Tackman, A. M., Kaplan, D. M., Raison, C. L., Sbarra, D. A., ..., Mehl, M. R. (2018). "Eavesdropping on happiness" revisited: A pooled, multisample replication of the association between life satisfaction and observed daily conversation quantity and quality. Psychological Science, 29(9), 1451-1462.

Milkman, K. L., Minson, J. A., \& Volpp, K. G. (2014). Holding the hunger games hostage at the gym: An evaluation of temptation bundling. Management Science, 60(2), 283-299.

Mills, S., Brown, H., Wrieden, W., White, M., \& Adams, J. (2017). Frequency of eating home cooked meals and potential benefits for diet and health: Cross-sectional analysis of a population-based cohort study. International Journal of Behavioral Nutrition and Physical Activity, 14(1), 1-11.

Mitchell, M. S., Orstad, S. L., Biswas, A., Oh, P. I., Jay, M., Pakosh, M. T., \& Faulkner, G. (2020). Financial incentives for physical activity in adults: Systematic review and meta-analysis. British Journal of Sports Medicine, 54(21), 1259-1268.

Morris, B. (2020). Why does zoom exhaust you? Science has an answer. The Wall Street Journal, https://www.wsj.com/articles/why-does-zoom-exhaust-you-science-has-an-answer-11590600269, Accessed: 2021-03-03

Mujcic, R., \& Oswald, A. J. (2016). Evolution of well-being and happiness after increases in consumption of fruit and vegetables. American Journal of Public Health, 106(8), 1504-1510.

Netz, Y., Wu, M.-J., Becker, B. J., \& Tenenbaum, G. (2005). Physical activity and psychological wellbeing in advanced age: A meta-analysis of intervention studies. Psychology and Aging, 20(2), 272.

Neuhaus, M., Healy, G. N., Fjeldsoe, B. S., Lawler, S., Owen, N., Dunstan, D. W., \& ...Eakin, E. G. (2014). Iterative development of Stand Up Australia: A multi-component intervention to reduce workplace sitting. International Journal of Behavioral Nutrition and Physical Activity, 11(1), 1-11.

NU. (2021). Dit bedrijf gunt werknemers een vergadervrije week. https://www.nu.nl/werk/6117930/ditbedrijf-gunt-werknemers-een-vergadervrije-week.html, Accessed: 2021-03-03.

Oppezzo, M., \& Schwartz, D. L. (2014). Give your ideas some legs: The positive effect of walking on creative thinking. Journal of Experimental Psychology: Learning, Memory, and Cognition, 40(4), 1142 .

Page, K. M., \& Vella-Brodrick, D. A. (2009). The 'what', 'why' and 'how' of employee well-being: A new model. Social Indicators Research, 90(3), 441-458.

Parker, K., Menasce Horowitz, J., \& Minkin, R. (2020). How the coronavirus outbreak has - and hasn't - changed the way Americans work. Pew Research Center, https://www.pewresearch.org/socialtrends/2020/12/09/how-the-coronavirus-outbreak-has-and-hasnt-changed-the-way-americanswork/, Accessed: 2021-03-03.

Peper, E., Wilson, V., Martin, M., Rosegard, E., \& Harvey, R. (2021). Avoid Zoom fatigue, be present and learn. NeuroRegulation, 8(1), 47-47.

Perlow, L. A., \& Porter, J. L. (2009). Making time off predictable-and required. Harvard Business Review, 87(10), 102-109. 
Proper, K., \& van Mechelen, W. (2008). Effectiveness and economic impact of worksite interventions to promote physical activity and healthy diet. World Health Organization.

Quintiliani, L., Sattelmair, J., \& Sorensen, G. (2007). The workplace as a setting for interventions to improve diet and promote physical activity. World Health Organization, 1-36.

Ragsdale, J. M., \& Beehr, T. A. (2016). A rigorous test of a model of employees' resource recovery mechanisms during a weekend. Journal of Organizational Behavior, 37(6), 911-932.

Reinach Wolf, C. (2020). Virtual platforms are helpful tools but can add to our stress. Psychology Today, https:/www.psychologytoday.com/ca/blog/the-desk-the-mental-health-lawyer/202005/virtual-platf orms-are-helpful-tools-can-add-our-stress, Accessed: 2021-03-03.

Rosales, R. M. (2015). Energizing social interactions at work: an exploration of relationships that generate employee and organizational thriving.

Royer, H., Stehr, M., \& Sydnor, J. (2015). Incentives, commitments, and habit formation in exercise: Evidence from a field experiment with workers at a Fortune-500 company. American Economic Journal: Applied Economics, 7(3), 51-84.

Sadoff, S., \& Samek, A. (2019). Can interventions affect commitment demand? a field experiment on food choice. Journal of Economic Behavior \& Organization, 158, 90-109.

Sadoff, S., Samek, A., \& Sprenger, C. (2020). Dynamic inconsistency in food choice: Experimental evidence from two food deserts. The Review of Economic Studies, 87(4), 1954-1988.

Salari, N., Hosseinian-Far, A., Jalali, R., Vaisi-Raygani, A., Rasoulpoor, S., Mohammadi, M., ..., Khaledi-Paveh, B. (2020). Prevalence of stress, anxiety, depression among the general population during the covid-19 pandemic: A systematic review and meta-analysis. Globalization and Health, 16(1), 1-11.

Schilbach, F. (2019). Alcohol and self-control: A field experiment in India. American Economic Review, 109(4), 1290-1322.

Schuna Jr, J. M., Swift, D. L., Hendrick, C. A., Duet, M. T., Johnson, W. D., Martin, C. K., ..., TudorLocke, C. (2014). Evaluation of a workplace treadmill desk intervention: a randomized controlled trial. Journal of Occupational and Environmental Medicine, 56(12), 1266-1276.

Shirom, A. (2003). The effects of work stress on health. The Handbook of Work and Healthpsychology, $2,63-82$.

Shockley, K. (2014). Telecommuting. SIOP White Paper Series, https:/www.siop.org/Portals/84/docs/ White\%20Papers/ScientificAffairs/telecommuting.pdf, Accessed: 2021-03-03

Shrestha, N., Kukkonen-Harjula, K. T., Verbeek, J. H., Ijaz, S., Hermans, V., \& Pedisic, Z. (2018). Workplace interventions for reducing sitting at work. Cochrane Database of Systematic Reviews, (6).

Slack. (2020). Moving beyond remote: Workplace transformation in the wake of Covid-19. https://slack. com/intl/de-de/blog/collaboration/workplace-transformation-in-the-wake-of-covid-19, Accessed: 2021-03-03.

Slaunwhite, J. M., Smith, S. M., Fleming, M. T., \& Fabrigar, L. R. (2009). Using normative messages to increase healthy behaviours. International Journal of Workplace Health Management.

Slutsky, J., Chin, B., Raye, J., \& Creswell, J. D. (2019). Mindfulness training improves employee wellbeing: A randomized controlled trial. Journal of Occupational Health Psychology, 24(1), 139.

Statista. (2020). Streaming in the U.S. - Statistics \& facts. https://www.statista.com/topics/1594/strea ming/, Accessed: 2021-03-03.

Thorndike, A. N., Sonnenberg, L., Riis, J., Barraclough, S., \& Levy, D. E. (2012). A2-phase labeling and choice architecture intervention to improve healthy food and beverage choices. American Journal of Public Health, 102(3), 527-533.

Tison, G. H., Avram, R., Kuhar, P., Abreau, S., Marcus, G. M., Pletcher, M. J., \& Olgin, J. E. (2020). Worldwide effect of Covid-19 on physical activity: A descriptive study. Annals of Internal Medicine, 173(9), 767-770.

Toyoda, M., Yokota, Y., Barnes, M., \& Kaneko, M. (2020). Potential of a small indoor plant on the desk for reducing office workers' stress. HortTechnology, 30(1), 55-63.

US Travel. (2019). Paid time off trends in the U.S. https://www.ustravel.org/sites/default/files/media_root/ document/Paid\%20Time\%20Off\%20Trends\%20Fact\%20Sheet.pdf, Accessed: 2021-03-03.

Umberson, D., \& Karas Montez, J. (2010). Social relationships and health: A flashpoint for health policy. Journal of Health and Social Behavior, 51(1_suppl), S54-S66.

Velema, E., Vyth, E. L., Hoekstra, T., \& Steenhuis, I. H. (2018). Nudging and social marketing techniques encourage employees to make healthier food choices: A randomized controlled trial in 30 worksite cafeterias in the Netherlands. The American Journal of Clinical Nutrition, 107(2), 236-246. 
Venema, T. A., Kroese, F. M., \& De Ridder, D. T. (2018). I'm still standing: A longitudinal study on the effect of a default nudge. Psychology \& Health, 33(5), 669-681.

Wansink, B., \& Sobal, J. (2007). Mindless eating: The 200 daily food decisions we overlook. Environment and Behavior, 39(1), 106-123.

WHO. (2020a). Healthy diet. https://www.who.int/news-room/fact-sheets/detail/healthy-diet, Accessed: 2021-03-03.

WHO. (2020b). WHO director-general's opening remarks at the media briefing on Covid-19 - 11 March 2020. https://www.who.int/director-general/speeches/detail/who-director-general-s-opening-remar ks-at-the-media-briefing-on-covid-19---11-march-2020, Accessed: 2021-03-03.

WHO. (2021). What is the WHO definition of health? https://www.who.int/about/who-we-are/frequentlyasked-questions, Accessed: 2021-03-03. Retrieved 2021-03-03, from https://www.who.int/about/ who-we-are/frequently-asked-questions

Wildermuth, K. (2018). Water proximity and its effect on consumption: In a corporate setting (Unpublished doctoral dissertation). Arizona State University.

Wolever, R. Q., Bobinet, K. J., McCabe, K., Mackenzie, E. R., Fekete, E., Kusnick, C. A., \& Baime, M. (2012). Effective and viable mind-body stress reduction in the workplace: A randomized controlled trial. Journal of Occupational Health Psychology, 17(2), 246.

Wright, K. B., Abendschein, B., Wombacher, K., O’Connor, M., Hoffman, M., Dempsey,M., ..., Shelton, A. (2014). Work-related communication technology use outside of regular work hours and work life conflict: The influence of communication technologies on perceived work life conflict, burnout, job satisfaction, and turnover intentions. Management Communication Quarterly, 28(4), 507-530.

Wright, T. A., \& Huang, C.-C. (2012). The many benefits of employee well-being in organizational research. Journal of Organizational Behavior, 33(8), 1188-1192.

Xie, J., Ma, H., Zhou, Z. E., \& Tang, H. (2018). Work-related use of information and communication technologies after hours (w_icts) and emotional exhaustion: A mediated moderation model. Computers in Human Behavior, 79, 94-104.

Zhang, H., \& Feinzig, S. (2017). Should I stay or should I go: Global insights into employees' decisions to leave their jobs. IBM Smarter Workforce Institute. 